\title{
Stress Evaluation of Dental Clinic Students and Its Related Factors
}

\author{
Zeinab Hamzeheil ${ }_{1}$, Hossein Aghili ${ }_{2}$, Amirmohammad Mahabadi ${ }_{3}$, \\ Soraya teimoori ${ }_{4}$, Roghaye Hakimian 5 ,Pedram Iranmanesh ${ }_{6}$
}

\section{ABSTRACT:}

Background: Nowadays dentistry has been discussed in the most of the studies as a challenge and stressful fields.

So the aim of this study was to evaluate the stress level of Dental clinic Students and its related factors in the two different periods of time with 5-years interval times.

Materials and methods: This descriptive-analytic cross sectional study was done at the two different periods of times and their results were compared. A questionnaire was given to the all dental clinic students in the middle of the academic term for the 2005-2006 and 2010-2011 years. Data analysis was performed by using SPSS software and consisted of descriptive, chi-square, student t-test and Anova (using Tukey, post Hock comparison and linear regression)

Results: Statistical population of this descriptive-analytic cross sectional study consisted of 124 clinical students included 74 females and 50 males $(\mathrm{P}=0.031)$ in the first step and 100 students included $61 \mathrm{females}$ and 39 males $(\mathrm{P}=0.028)$ in second assess. Overall the main stress factors were qualification created by professors of the departments, oral medicine department, exams and grades, restorative department, orthodontic department, large volume of educational materials.

Conclusion: Dentistry and specially it education is a stressful experience and we should try to create a calm environment without the additional stress.

Keywords: dental student, stress factors, department

\section{INTRODUCTION:}

\section{Background:}

With the improvement of science in recent decades, education and the issues related to it, has had a special place among scientific topics. Stress has been evaluated as an important factor in education.

\footnotetext{
${ }^{1}$ General Dentist, DDS, Yazd, Iran

${ }^{2}$ Associate professor of orthodontic department, dental school, shahid sadoughi university of medical science,Yazd,Iran

${ }^{3}$ General Dentist, DDS, Yazd, Iran

${ }^{4}$ librarian and search literacher officer, dental school, shahid sadoughi university of medical science, Yazd,Iran.5, Dental Student research, Isfahan University of medical sciences Isfahan, Iran

${ }^{5}$ General Dentist, DDS, Yazd, Iran

${ }^{6}$ General Dentist, DDS, Yazd, Iran
}

(C) 2015, Z Hamzeheil, H Aghili, A Mahabadi, S teimoori, R Hakimian, P Iranmanesh; licensee IJIP. This is an Open Access Research distributed under the terms of the Creative Commons Attribution License (http://creativecommons.org/licenses/by/2.0), which permits unrestricted use, distribution, and reproduction in any Medium, provided the original work is properly cited. 


\section{Stress evaluation of Dental clinic Students and its related factors}

The term "stress" describes external demands (physical or mental) on an individual's physical and psychological well-being(Atkinson et al., 1991).

Nowadays dentistry has been discussed in most of the studies as a challenge and stressful fields(Freeman et al., 1995, Naidu et al., 2002).

Musculoskeletal complaints are much in dentists that reporting by them as a psychological stress(Ekberg et al., 1994, Rundcrantz et al., 1991).

The number of studies pay attention to psychological stress and stress-related health problems in the dental population, cause the dental to be as a rather stressful profession(Myers and Myers, 2004, Wilson et al., 1998). The high levels of stress could lead to burnout, with typical characteristics of emotional exhaustion, depersonalization and reduced personal accomplishment in the long period of time(Rada and Johnson-Leong, 2004).dental students experience high levels of stress among training in their educational process, so it can be the cause of this occupational stress(Heath et al., 1999, Westerman et al., 1993, Newton et al., 1994, Rajab, 2001).

Expressing considerable stress symptoms during training of dental student would have some results such as depression, anxiety, substance misuse, absenteeism, diminished work efficiency, and burnout(Heath et al., 1999, Freeman et al., 1995, Kent, 1987, Wexler, 1978, Grandy et al., 1988, Newbury-Birch et al., 2002).

Generally, the most harmful effect of stress is disrupting thinking and learning performance (Grandy et al., 1989, Goldstein, 1980, Akbari et al., 2011).

Studies include many factors that are reported by specific stress factors such as: patient Management; the need to meet academic and clinical requirements; interaction with student colleagues, clinical teachers, and support staff; and relationships with partners, friends, and family or examination and grades, fear of failing or falling behind were the highest ranked stress factors reported for dental students(Heath et al., 1999, Westerman et al., 1993, Rajab, 2001, Sanders and Lushington, 1999, Yap et al., 1996).

Contemporary curricula require dental students to attain diverse proficiencies, including the acquisition of theoretical knowledge, clinical competencies, and interpersonal skills (Kumar et al., 2009).

In fact identification of stress factors for improving quality of dental education is necessary(Polychronopoulou and Divaris, 2009).

Identifying potential stress sources in order to address them effectively is an important issue for dental schools. Clinical and theoretical part of dentistry can be as a strong or a weak stress factor that effect on student training so paying attention to that is necessary in this case.

So the aim of this study was to evaluate the stress level of Dental clinic Students and its related factors in the two different periods of time with 5-years interval times in the Shahid Sadoughi University of Medical Sciences- Yazd, Iran. 


\section{METHOD AND MATERIAL:}

This descriptive-analytic cross sectional study was done in the two different periods of time. in this study questionnaires were given to the all dental clinic students of the Shahid Sadoughi University of Medical Sciences ,Yazd, Iran in the middle of the academic term for the 2005-2006 and 2010-2011 years.

Already for distribution of questionnaires, students were justified about the protocol. Participation in the study was voluntary and their name remained anonymous.

In the 1th and 2th assess respectively 124 and 100 clinical students participated in the study.

Also the study approved by the medical ethics committee of Shahid Sadoughi University of medical science, Iran, Yazd.

A questionnaire was included demographic data (age, gender, year of undergraduate study) and questions according to a scientific committee on the basis of a DES questionnaire (dental environmental stress) and some stress factors that during a preliminary study had introduced as effective factors on the amount of student's stress. Also stress level of the various clinical lessons were recorded at 10 questions by students.

Students were asked to assess the questionnaire items as "not stressfull", "somewhat stressful", "quite stressfully" and "very stressful" on a four point likert scale. Data analysis was performed by using SPSS software and consisted of descriptive, chi-square, student t-test, Anova (using Tukey, post Hock comparison and linear regression)

\section{RESULTS:}

This study was done in 2steps of the academic term for the 2005-2006 and 2010-2011 years and their results were compared.

Statistical population of this descriptive-analytic cross sectional study consisted of 124 clinical students included $74 \mathrm{females}$ and 50 males $(\mathrm{P}=0.031)$ in the first step and 100 students included 61 females and 39 males $(\mathrm{P}=0.028)$ in the second assess that their difference was not significant. The mean age of the participated individual in first and second steps was $24.49 \pm 5.7$ and $24.93 \pm 4.1$ yearsrespectively.

In this study the level of stress in female significantly was higher than males $(\mathrm{P}=0.001)$ but there was no significant relationship between age and level of stress $(\mathrm{P}=0.14)$ also with years of education. $(\mathrm{P}=0.206)$

Six main stress factors in first evaluation were qualification created by professors of the departments, oral medicine department, exams and grades, restorative department, orthodontic department, large volume of educational materials and in second assess were oral medicine department, exams and grades, qualification created by professors of the department, large 


\section{Stress evaluation of Dental clinic Students and its related factors}

volume of educational materials, rules and procedures problematic school and orthodontic department. (Table 1)

Table1: The frequency distribution of most stress factors in academic terms in two periods of time

\begin{tabular}{|l|l|l|l|l|}
\hline & 2005-2006 & Percentage & 2010-2011 & Percentage \\
\hline $\mathbf{1}$ & $\begin{array}{l}\text { Qualification created by a } \\
\text { professor of the department }\end{array}$ & 75 & Oral medicine department & $91 / 8$ \\
\hline $\mathbf{2}$ & Oral medicine department & 71 & Exams and grades & 72 \\
\hline $\mathbf{3}$ & Exams and grades & 69.4 & $\begin{array}{l}\text { Qualification created by a } \\
\text { professor of the department }\end{array}$ & 67 \\
\hline $\mathbf{4}$ & Restorative department & 67.7 & $\begin{array}{l}\text { Large volume of educational } \\
\text { materials }\end{array}$ & 61 \\
\hline $\mathbf{5}$ & Orthodontic department & 64.5 & $\begin{array}{l}\text { Rules and procedures } \\
\text { problematic school }\end{array}$ & 54.5 \\
\hline $\mathbf{6}$ & $\begin{array}{l}\text { Large volume of educational } \\
\text { materials }\end{array}$ & 63.7 & \begin{tabular}{l} 
Orthodontic department \\
\hline
\end{tabular}
\end{tabular}

In the first evaluation departments such as oral medicine, restorative and orthodontic were reported as highest level of stress but in second step departments such as oral medicine, orthodontic and endodontic had the highest level of stress. In table 2 has been shown stress level of various departments in dental school. (Table 2)

Table 2 : The frequency distribution based on the stress level of various departments of dental school.

\begin{tabular}{|l|l|l|l|l|l|}
\hline & department & $\mathbf{2 0 0 5 - 2 0 0 6}$ & $\mathbf{2 0 1 0 - 2 0 1 1}$ & P value & Significant difference \\
\hline $\mathbf{1}$ & Oral medicine & $71 \%$ & $91.8 \%$ & 0.001 & $\uparrow$ \\
\hline $\mathbf{2}$ & Orthodontic & $64.5 \%$ & $53.4 \%$ & 0.127 & - \\
\hline $\mathbf{3}$ & Endodontic & $62.6 \%$ & $47.5 \%$ & 0.028 & $\downarrow$ \\
\hline $\mathbf{4}$ & Restorative & $67.7 \%$ & $31.3 \%$ & $<0.001$ & $\downarrow$ \\
\hline $\mathbf{5}$ & Pediatric dentistry & $42.7 \%$ & $41.8 \%$ & 0.539 & - \\
\hline $\mathbf{6}$ & Periodontology & $25.8 \%$ & $44.5 \%$ & 0.007 & $\uparrow$ \\
\hline $\mathbf{7}$ & Prosthesis & $19.4 \%$ & $26.1 \%$ & 0.264 & - \\
\hline $\mathbf{8}$ & Radiology & $12.1 \%$ & $27.7 \%$ & 0.011 & $\uparrow$ \\
\hline $\mathbf{9}$ & surgery & $28.2 \%$ & $2.4 \%$ & $<0.001$ & $\downarrow$ \\
\hline $\mathbf{1 0}$ & pathology & $12.1 \%$ & $13 \%$ & 0.438 & - \\
\hline
\end{tabular}

\section{DISCUSSION:}

This study was done to evaluate stress-provoking factors among the dental clinic students and its related factors at the two different periods of times with 5 years interval times in the Shahid Saduoghi University of Medical Sciences, Yazd - Iran. A course based study. 


\section{Stress evaluation of Dental clinic Students and its related factors}

In each society`s attention to corporeal, psychological, society health and providing necessary planning for making healthy life is surety of society for future years.

Since new education or its continuing is a critical and delicate situation in a person`s life and usually this period is associated with great changes in human and societal relationships(Roseman et al., 1995). The results of this study support the existing evidence in the literature, indicating that dental students are subject to numerous work-related and academic stressors (Thornton et al., 2004, Grandy et al., 1988, Anders P, 1985, Ng et al., 2003).

Generally can be say some part of this stress is about dentistry field and some of that is due to training part. Stress can lead to depression, anxiety, substance misuse, absenteeism, diminished work efficiency, and burn out (Heath et al., 1999, Freeman et al., 1995, Kent, 1987). So identifying potential stress sources and addressing them effectively is imperative for dental schools.

In this study, beside the common causes of stress, training departments were assessed in the amount of stress. In the first evaluation oral medicine, restorative and orthodontic departments caused more stress whereas in next part oral medicine, orthodontic and endodontic departments have been expressed as major department stressor.

Restorative department was the fourth stressor and second department stressor in first survey but the Stress level of this department $(\mathrm{P}<0.001)$, endodontic $(\mathrm{P}=0.028)$ and surgery $(\mathrm{P}<0.001)$ departments significantly had declined in this five year period whereas endodontic department ranked the third department stressor in second evaluation.

Oral medicine department was the second stressor in the first survey and first stressor in second survey and it was the first department stressor in both evaluations. An exclamation point is that it`s stress level increased significantly in this interval $(\mathrm{P}=0.001)$.

As well as stress level of Periodontology $(\mathrm{P}=0.007)$ and radiology $(\mathrm{P}=0.011)$ departments raised significantly.

Orthodontic department was the fifth stressor and sixth stressor in first and second survey also second department stressor in both evaluations. The stress level of this department decreased but not significantly during this period $(\mathrm{P}=0.127)$.

The stress level of pediatric dentistry $(\mathrm{P}=0.539)$, pathology $(\mathrm{P}=0.438)$ and prosthesis $(\mathrm{P}=0.264)$ departments did not alter significantly.

Actually determination of stress causes by each department requires a more detailed and comprehensive study but it may stress causes in such departments with highest stress level is associated with main stress causes in this study such as qualification created by professors of the department, exams and grades and large volume of educational materials. 
Other studies have also been reported gender differences so that female students experiencing more stress than males(Heath et al., 1999, Westerman et al., 1993).same our study that females have a higher level of stress significantly than males. These levels of female dental student's stress have been explained by being related to the social construct of masculinity in which males are less expressive of stress but subsequently more vulnerable to health risks(Sanders and Lushington, 1999). Furthermore ,It has been suggested by Lazarus and Folkman(Lazarus RS, 1984)that, the way in which students cope with the overall demands of education, rather than the specific demands per se, may be the primary determinant of their psychological distress(Wolf, 1994).Hence, it`s not the specific stressor but rather the student management and coping strategy that determine the impact or disturbance caused by the stress.

Also some studies show that the levels of total student's stress remain constant during four or five year program and our study have not shown any difference in level of student's stress during their educational terms.

However others reported a slight increase in overall students`stress levels when they progress towards graduation(Heath et al., 1999, Sanders and Lushington, 1999).

The highest ranked stresses that are reported by dental students are examination and grades, fear of failing that in our study were the first highest level of stress in the both evaluations same the result of Naidu and et al`s study(Naidu et al., 2002) also among six stressors a large amount of training was the sixth in first evaluation and fourth in 2 th one.

Humphris et al(Humphris et al., 2002) and Pöhlmann et al(Pöhlmann et al., 2005) presented evidence supporting the association of such aspects of education as examinations and clinical training with student stress.

In this study exam and grades were one of the main stressors in the both evaluations same Naidu and et al 's study(Naidu et al., 2002). Also the large volume of educational materials was in six and fourth grade in the first and second evaluation respectively.

It is essential to find a clearer understanding about a positive academic environment and educational roles that are effective on students`stress perception(Divaris et al., 2008, Victoroff and Hogan, 2006).

Goldstein(Goldstein, 1980) and Bradley et al(Bradley et al., 1989) in their investigations evaluated some factors of specific stress-provoking within the school environment also they did not relate the observed variance in overall stress.

In addition to, in our study one of the most important stresses in both evaluations was the qualification that the professors of departments make it. The Polychronopoulou's study shows that Faculty and administration would be a worrying factor in big university but a positive academic environment could be an effective factor to reducing student's stress(Polychronopoulou and Divaris, 2009, Divaris et al., 2008).

In this study rules and procedures problematic school defined as the fourth stressor in 2th evaluation like Naidu et al`s study(Naidu et al., 2002) that introduced them as a stressor for dental students in clinical terms.

Rules and management of school can be directly influenced the educational system, training procedures of departments, timing and manner of exams, student assessment, policies to insure the patient, equipment needed and access to appropriate laboratory for students and other factors. These cases were most notable stressors in this study. In addition to Creating a suitable 


\section{Stress evaluation of Dental clinic Students and its related factors}

environment, Stress management courses and increasing coping skill are the duty of legislators and executives these laws in the dental school.

It's necessary to say maybe some of the regulation of dental education in across the country are obstacle to the measure taken within the academic for upgrading these stressors.

The reconsideration of the existing educational system towards more students centeral orientation can help collaborative learning and interpersonal support among students which may have a protective influence against difficulties faced in university(KAUFMAN et al., 1982).

Significant differences in a multinational student sample were detected by Pau et al(Pau et al., 2007), and also some of the investigators perceived underlying personality, societal and cultural differences affect as occupationally stressful events(Pau et al., 2007, McCarty et al., 1999, Daniels, 2004).

Therefore, it may be argued that the observed differences should not be solely associated with educational or demographic parameters, but that sociocultural or other extracurricular factors play a role. Thus, may influence on the student's perceiving, reacting, and responding way to stressful events. Along these lines, emotional intelligence(Pau et al., 2007, Naidoo and Pau, 2008) and social support(Muirhead and Locker, 2008) have been identified as important correlates of stress perceptions among dental students recently.

Therewith in this study we used a questionnaire modified based on DES questionnaire, indigenous cultures and to the emphasis on assessing of departments while in other studies generally used in the DES questionnaire(Polychronopoulou and Divaris, 2009) that it Could be due to the differences of some obtained results.

There were always some stress creators that the level of them did not change during this period interval and they were at a moderate grade of provoking items. Stressors such as reduce the number of patients, lack of patient cooperative, time delivery work to the patient ,loss of patient during labor, responsibility for comprehensive treatment, lack of access to some of the dental equipment, lack of access to laboratories, incorrect assessment of student's practical work by professors, disagreement between the professors of the departments for treatment plan and Sufficient time between exams that it's essential to consider interfering of these factors for reducing stress level of students.

Identifying stress factors in different stages of education, especially in the clinical courses are required but it is not enough, after identifying these factors, students and officials should be eliminated these stressor. Because this stress beside the effect on the student's learning and their quality of work, has affected their physical and mental health and quality of their career in the future(Myers and Myers, 2004, Wilson et al., 1998, Grandy et al., 1989, Goldstein, 1980).

A broad spectrum of intervention studies has evaluated such programs for dental students, including specific courses, stress-reduction sessions and so on(Polychronopoulou and Divaris, 2005). as a six year study in the USA which compared the effect of a "relaxed teaching method" 


\section{Stress evaluation of Dental clinic Students and its related factors}

to "traditional approaches" on student performance and well-being in preclinical operative technique courses (Naidu et al., 2002).

A significant benefit to the student well-being in courses using the "relaxed teaching method was reported" (Naidu et al., 2002). This method included the removal fear of course failure, the encouragement of active student/teacher interaction, a reduction of intimidation and confrontation, and a maxi mixing of supportive teaching methodologies.

\section{CONCLUSION:}

At a glance, although individual differences are effected in stress receive and its response but dentistry and specially it education is a stressful experience and we must try to create a calm environment without the additional stress and the proper relationship between students and professors, the stress can be used for learning and performance.

Comments: Appropriate management of professors, assessment and exams related to academic context and student ability, Consideration of appropriate educational content with training needs and the ability of students, sufficient time and appropriate programs for examining and taking the appropriate decision for providing the number of patients needed could be having an effective role in reducing these stresses. Also should be to consider learning about ways coping against stress to the dentistry students.

\section{REFERENCES:}

1. AKBARI, M., NEJAT, A., DASTORANI, S. \& ROUHANI, A. 2011. Evaluation of Stress Level and Related Factors among Students of Mashhad Dental School (Iran) in Academic Year of 2008-2009. Journal of Mashhad Dental School, 35, 3.

2. ATKINSON, J., MILlAR, K., KAY, E. \&BLINKHORN, A. 1991. Stress in dental practice. Dental update, 18, 60.

3. EKBERG, K., BJÖRKQVIST, B., MALM, P., BJERRE-KIELY, B., KARLSSON, M. \& AXELSON, O. 1994. Case-control study of risk factors for disease in the neck and shoulder area. Occupational and Environmental Medicine, 51, 262-266.

4. FREEMAN, R., MAIN, J. \& BURKE, F. 1995. Occupational stress and dentistry: theory and practice. Part I. Recognition. British Dental Journal, 178, 214-217.

5. GOLDSTEIN, M. B. 1980. Interpersonal support and coping among first-year dental students. Journal of Dental Education, 44, 202-205.

6. GRANDY, T. G., WESTERMAN, G., LUPO, J. \& COMBS, C. 1988. Stress symptoms among third-year dental students. Journal of dental education, 52, 245-249. 
7. AKBARI, M., NEJAT, A., DASTORANI, S. \& ROUHANI, A. 2011. Evaluation of Stress Level and Related Factors among Students of Mashhad Dental School (Iran) in Academic Year of 2008-2009. Journal of Mashhad Dental School, 35, 3.

8. ANDERS P, T. L., DAVIS E, BREWER J 1985. Educational environment, perceived stress, and symptoms of distress among dental students at three schools. J Dent Educ, 49, 40.

9. ATKINSON, J., MILLAR, K., KAY, E. \& BLINKHORN, A. 1991. Stress in dental practice. Dental update, 18, 60.

10. BRADlEY, I. F., ClARK, D., EISNER, J., DE GRUCHY, K., SINGER, D., HINKLEMAN, K., GELSKEY, S. \& WOOD, W. 1989. The student survey of problems in the academic environment in Canadian dental faculties. Journal of dental education, 53, 126131.

11. DANIELS, K. 2004. Perceived risk from occupational stress: a survey of 15 European countries. Occupational and environmental medicine, 61, 467-470.

12. DIVARIS, K., BARLOW, P., CHENDEA, S., CHEONG, W., DOUNIS, A., DRAGAN, I., HAMLIN, J., HOSSEINZADEH, L., KUIN, D. \& MITRIRATTANAKUL, S. 2008. The academic environment: the students' perspective. European Journal of Dental Education, 12, 120-130.

13. EKBERG, K., BJöRKQVIST, B., MALM, P., BJERRE-KIELY, B., KARLSSON, M. \& AXELSON, O. 1994. Case-control study of risk factors for disease in the neck and shoulder area. Occupational and Environmental Medicine, 51, 262-266.

14. FREEMAN, R., MAIN, J. \& BURKE, F. 1995. Occupational stress and dentistry: theory and practice. Part I. Recognition. British Dental Journal, 178, 214-217.

15. GOLDSTEIN, M. B. 1980. Interpersonal support and coping among first-year dental students. Journal of Dental Education, 44, 202-205.

16. GRANDY, T. G., WESTERMAN, G., LUPO, J. \& COMBS, C. 1988. Stress symptoms among third-year dental students. Journal of dental education, 52, 245-249.

17. GRANDY, T. G., WeSTERMAN, G. H., COMBS, C. E. \& TURNER, C. H. 1989. Perceptions of stress among third-year dental students. Journal of dental education, 53, 718721.

18. HEATH, J., MACFARLANE, T. \& UMAR, M. 1999. Perceived sources of stress in dental students. Dental update, 26, 94. 
19. HUMPHRIS, G., BLINKHORN, A., FREEMAN, R., GORTER, R., HOAD-REDDICK, G., MURTOMAA, H., O'SUlliVAN, R. \& SPLIETH, C. 2002. Psychological stress in undergraduate dental students: baseline results from seven European dental schools. European journal of dental education, 6, 22-29.

20. KAUFMAN, A., KLEPPER, D., OBENSHAIN, S. S., VOORHEES, J. D., GALEY, W., DUBAN, S., MOORE-WEST, M., JACKSON, R., BENNETT, M. \& WATERMAN, R. 1982. Undergraduate medical education for primary care: a case study in New Mexico. Southern Medical Journal, 75, 1110-1117.

21. KENT, G. 1987. Stress among dentists. In: PAYNE, R. \& FIRTH-COZEN, J. (eds.) Stress in health professionals. Chichester: Wiley.

22. KUMAR, S., DAGLI, R., MATHUR, A., JAIN, M., PRABU, D. \& KULKARNI, S. 2009. Perceived sources of stress amongst Indian dental students. European journal of dental education, 13, 39-45.

23. LAZARUS RS, F. S., 1984. 1984. Stress, appraisal and coping., NewYork, Springer.

24. MCCARTY, C. A., WEISZ, J. R., WANITROMANEE, K., EASTMAN, K. L., SUWANLERT, S., CHAIYASIT, W. \& BAND, E. B. 1999. Culture, coping, and context: Primary and secondary control among Thai and American youth. Journal of Child Psychology and Psychiatry, 40, 809-818.

25. MUIRHEAD, V. \& LOCKER, D. 2008. Canadian dental students' perceptions of stress and social support. European journal of dental education, 12, 144-148.

26. MYERS, H. \& MYERS, L. 2004. 'It's difficult being a dentist': stress and health in the general dental practitioner. British dental journal, 197, 89-93.

27. NAIDOO, S. \& PAU, A. 2008. Emotional intelligence and perceived stress. SADJ: journal of the South African Dental Association= tydskrif van die Suid-Afrikaanse Tandheelkundige Vereniging, 63, 148.

28. NAIDU, R. S., ADAMS, J. S., SIMEON, D. \& PERSAD, S. 2002. Sources of stress and psychological disturbance among dental students in the West Indies. Journal of dental education, 66, 1021-1030.

29. NEWBURY-BIRCH, D., LOWRY, R. \& KAMALI, F. 2002. The changing patterns of drinking, illicit drug use, stress, anxiety and depression in dental students in a UK dental school: a longitudinal study. British dental journal, 192, 646-649. 
30. NEWTON, J., BAGHAIENAINI, F., GOODWIN, S., INVEST, J. \& LUBBOCK, M. 1994. Stress in dental school: a survey of students. Dental update, 21, 162.

31. NG, V., KOH, D., MOK, B., CHIA, S.-E. \& LIM, L.-P. 2003. Salivary biomarkers associated with academic assessment stress among dental undergraduates. Journal of Dental Education, 67, 1091-1094.

32. PAU, A., ROWLAND, M. L., NAIDOO, S., ABDULKADIR, R., MAKRYNIKA, E., MORARU, R., HUANG, B. \& CROUCHER, R. 2007. Emotional intelligence and perceived stress in dental undergraduates: a multinational survey. Journal of dental education, 71, 197204.

33. PöHLMANN, K., JONAS, I., RUF, S. \& HARZER, W. 2005. Stress, burnout and health in the clinical period of dental education. European journal of dental education, 9, 78-84.

34. POLYCHRONOPOULOU, A. \& DIVARIS, K. 2005. Perceived sources of stress among Greek dental students. Journal of dental education, 69, 687-692.

35. POLYCHRONOPOULOU, A. \& DIVARIS, K. 2009. Dental students' perceived sources of stress: a multi-country study. Journal of dental education, 73, 631-639.

36. RADA, R. E. \& JOHNSON-LEONG, C. 2004. Stress, burnout, anxiety and depression among dentists. The Journal of the American Dental Association, 135, 788-794.

37. RAJAB, L. 2001. Perceived sources of stress among dental students at the University of Jordan. Journal of dental education, 65, 232-241.

38. ROSEMAN, I. J., DHAWAN, N., RETTEK, S. I., NAIDU, R. \& THAPA, K. 1995. Cultural differences and cross-cultural similarities in appraisals and emotional responses. Journal of Cross-Cultural Psychology, 26, 23-48.

39. RUNDCRANTZ, B.-L., JOHNSSON, B. \& MORITZ, U. 1991. Pain and discomfort in the musculoskeletal system among dentists. A prospective study. Swedish dental journal, 15, 219.

40. SANDERS, A. \& LUSHINGTON, K. 1999. Sources of stress for Australian dental students. Journal of dental education, 63, 688-697.

41. ThORNTON, L. J., STUART-BUtTlE, C., WYSZYNSKI, T. C. \& WILSON, E. R. 2004. Physical and psychosocial stress exposures in US dental schools: the need for expanded ergonomics training. Applied ergonomics, 35, 153-157. 


\section{Stress evaluation of Dental clinic Students and its related factors}

42. VICTOROFF, K. Z. \& HOGAN, S. 2006. Students' perceptions of effective learning experiences in dental school: a qualitative study using a critical incident technique. Journal of Dental Education, 70, 124-132.

43. WESTERMAN, G. H., GRANDY, T., OCANTO, R. \& ERSKINE, C. 1993. Perceived sources of stress in the dental school environment. Journal of dental education, 57, 225-231.

44. WEXLER, M. 1978. Mental health and dental education. Journal of dental education, 42, 74-77.

45. WILSON, R., COWARD, P., CAPEWELL, J., LAIDLER, T., RIGBY, A. \& SHAW, T. 1998. Perceived sources of occupational stress in general dental practitioners. British dental journal, 184, 499-502.

46. WOLF, T. M. 1994. Stress, coping and health: enhancing well-being during medical school. Medical Education, 28, 8-17.

47. YAP, A., BHOLE, S. \& TEO, C. 1996. A cross-cultural comparison of perceived sources of stress in the dental school environment. Journal of dental education, 60, 459-464. 